\title{
A construção social de um sistema de mobilidade inteligente: mapeando controvérsias no caso do Swisspass
}

\author{
The social construction of a smart mobility system: \\ mapping controversies in the case of SwissPass
}

Marcela de Moraes Batista Simão [l]

Rodrigo José Firmino [II]

\section{Resumo}

A ideia prevalente de cidades inteligentes pressupõe o uso de tecnologias digitais para uma gestão supostamente mais eficiente das dinâmicas urbanas. Há uma necessidade científica de se conhecer tais processos, a partir das ciências sociais. Dentre os vários setores da gestão urbana, o de mobilidade é um dos mais sensíveis a mudanças tecnológicas. 0 principal objetivo deste artigo é desconstruir historicamente o projeto SwissPass, e compreender suas nuanças sociotécnicas por meio da identificação de grupos sociais e interesses, bem como pelo mapeamento das controvérsias envolvidas na implementação desse sistema de mobilidade inteligente na Suíça. Os resultados indicam disputas de poder e um domínio do processo por grandes empresas estatais de transporte, além da dissipação das controvérsias por estratégias de convencimento concentradas em seu suposto papel inovador.

Palavras-chave: mapeamento de controvérsias; construção social das tecnologias; SwissPass; mobilidade inteligente; disputas de poder.

\begin{abstract}
The prevalent idea of smart cities presupposes the use of digital technologies for an alleged more efficient management of urban dynamics and systems. There is a scientific need to know more about such processes in the social sciences. Among the various sectors of urban management, mobility is one of the most sensitive to technological changes. The aim of this article is to historically deconstruct the SwissPass project and to understand its sociotechnical nuances through the identification of social groups and interests, as well as through the mapping of controversies involved in the implementation of this smart mobility system in Switzerland. The results indicate power disputes, dominance of the process by large, state-run transport companies, and dissipation of the controversies by persuasion strategies focusing on its alleged innovative role.
\end{abstract}

Keywords: controversy mapping; social construction of technologies; SwissPass; smart mobility; power disputes 


\section{Introdução}

Apesar de existirem diversas vertentes que estudam a relação da tecnologia com a cidade, é inegável que as tecnologias digitais trouxeram mudanças para o espaço urbano (Graham e Marvin, 1996; Graham e Marvin, 2001; Firmino, 2011; Firmino, Duarte e Ultramari, 2010). Segundo Aibar e Bijker (1997), o entendimento das complexas relações entre espaço urbano e tecnologia começou a ganhar visibilidade a partir de uma edição especial sobre cidade e tecnologia do periódico Journal of Urban History, em 1979. Na introdução dessa edição especial, Tarr (1979) argumenta que a tecnologia foi esquecida por muitos anos pelos historiadores e estudiosos da cidade, que a consideravam algo exclusivo a construção da cidade, com pouca relação com as outras áreas relativas ao urbano, tornando a temática "tecnologias e espaço urbano" um campo pouco atraente. 0 próprio autor fez parte de um grupo de historiadores norte-americanos que aproximou e ampliou os estudos sobre a tecnologia e o espaço urbano. Rose e Tarr (2004) sustentam que a visibilidade dada às tecnologias abriu novos caminhos e estudos.

Nesse contexto, algumas escolas passaram a estudar tal relação, para além do simples relato historiográfico, com abordagens da sociologia, filosofia, ciência política, direito, geografia e outras áreas ligadas ao campo Ciência, Tecnologia e Sociedade (CTS), que passou a considerar o tema das relações sociotécnicas que constituem o espaço urbano e seus aspectos culturais, sociais e históricos.

Aibar e Bijiker (1997) propuseram um estudo sócio-histórico para o plano de expansão da cidade de Barcelona, do século XIX, a partir de uma abordagem construtivista (Bijker, 1995) e da interpretação do plano de expansão como um tipo específico de tecnologia e da cidade de Barcelona como um artefato em desenvolvimento. Dentre as muitas facetas dessa história técnica, social, cultural e econômica, esse estudo destaca as diversas matizes das relações de poder dos vários grupos envolvidos na controvérsia da concepção e implantação dessa "nova tecnologia", o plano de expansão.

0 presente artigo adota um caminho semelhante no que se refere à interpretação de relações de poder para a constituição de um plano abrangente de mobilidade inteligente como tecnologia socialmente construída. 0 ambiente não é mais o da Revolução Industrial, de meados do século XIX, ou da crença modernista na máquina que se seguiu ao longo de quase todo o século XX e orientou planos diretores amplos e abrangentes no Brasil e em todo mundo ocidental. Escolhemos, como objeto de estudo, particularidades do que tem sido considerada a grande marca midiática e corporativa do urbanismo do século XXI, a cidade inteligente, marcada por redes autônomas e interconectadas, governada por complexos algoritmos computacionais capazes de lidar com grandes volumes de dados e informações na gestão de sistemas urbanos e tomadas de decisão.

Luque-Ayala e Marvin (2015) apontam para a predominância contemporânea do que chamaram de fenômeno smartness, que engloba os conceitos de cidade inteligente, casa inteligente, edifício inteligente, mobilidade inteligente, carro inteligente e energia inteligente, dentre outros aspectos, como fatores determinantes de um tal ideal urbanístico inteligente (pautado pelo mercado tecnológico, por lógicas empresariais de gestão e pelo marketing urbano). 
Uma das questões norteadoras deste artigo, tendo em vista esses fatores determinantes, recai sobre a identificação de relações de poder na construção sociotécnica da cidade inteligente contemporânea. 0 foco se dá sobre um serviço de mobilidade baseado em cartões inteligentes (smart cards), implantado de forma abrangente na Suíça, o SwissPass (lançado em 2015). 0 projeto e sua implementação (ainda em curso) envolvem diversas controvérsias por disputas de interesses diversos, de natureza local, regional e nacional. Assim, pretende-se realizar um mapeamento de controvérsias (Venturini, 2009) à luz da teoria da Construção Social das Tecnologias (Bijker e Law, 1992; Pinch e Bijker, 1987) para a compreensão das relações de poder ativadas pelos diferentes grupos sociais relevantes envolvidos na promoção e na resistência à efetivação do SwissPass em todo o país.

Esse "mapeamento" envolvendo o SwissPass e as relações de poder sobre um aspecto específico da cidade inteligente é realizado em quatro partes, além desta introdução e das conclusões. Na primeira seção, dedica-se a uma breve revisão das correntes teóricas ligadas à geografia e ao planejamento urbano que apontam para a caracterização de um certo "urbanismo inteligente". Na sequência, o texto focará na delimitação das categorias analíticas utilizadas no estudo do SwissPass, baseadas nos conceitos de governamentalidade e disputas de poder em Foucault. A terceira seção descreve a metodologia empregada no estudo empírico, e a quarta está dedicada aos passos analíticos para a proposta do mapeamento de controvérsias e grupos sociais relevantes no caso do SwissPass.

\section{Urbanismo inteligente?}

0 conceito de cidade inteligente pode ser visto como uma resposta mais eficiente ao protocolo de Kyoto, criado em 1998, no qual foram apresentados desafios climáticos com desdobramentos para o ambiente urbano. Gao et al. (2016) defendem que o protocolo de Kyoto alertou o mundo para a criação de novas soluções para os problemas climáticos, tendo como uma das respostas a criação de sistemas mais inteligentes com foco no meio ambiente, como a energia inteligente.

A partir disso, inúmeras interpretações surgiram na tentativa de qualificar o que poderia ser interpretado como inteligente no processo de planejamento e desenvolvimento urbano. Segundo Komninos (2011), a cidade inteligente é um território capaz de reagir aos problemas de forma inteligente e criativa usando especialmente as Tecnologias da Informação e Comunicação (TICs) para proporcionar qualidade de vida aos cidadãos, com informações e dados que alimentam os diversos subsistemas que compõem uma cidade. Para Nam e Pardo (2011), a cidade inteligente é uma nova forma de desenvolvimento urbano com foco em inovação. Batty et al. (2012) consideram a cidade inteligente uma resposta das cidades ao crescimento dos seus problemas urbanos, por meio do uso de tecnologias inteligentes para solucioná-los. Harrison et al. (2010) defendem que a cidade inteligente está ligada à capacidade de coletar dados e integrá-los ao mundo "real" por meio de plataformas que auxiliam a cidade a se tornar eficiente. E, para Hall (2000), a cidade inteligente é um sistema composto de 
uma estrutura tecnológica capaz de monitorar e otimizar o que a cidade precisa, como infraestrutura urbana, sistemas de água, esgoto e energia, aeroportos, transportes, etc., com foco em manter os sistemas operando com qualidade e eficiência.

Nesse ambiente especulativo, no qual o "inteligente" se torna um adjetivo qualificativo de uso eficiente de novas tecnologias na tentativa de resolver velhos problemas urbanos, a grande pergunta passa a ser o que não é inteligente na nova cidade inteligente (Hollands, 2008). Luque-Ayala e Marvin (2015) alertam para os riscos e desafios dessa nova era do urbanismo, considerada, por eles, como um fenômeno de âmbito global na medida em que este é composto por diversos atores multinacionais, em especial grandes corporações de tecnologias da informação (IBM, Samsung, Cisco, Google, Microsoft, Intel, Oracle, etc.).

$\mathrm{Na}$ origem desse fenômeno, Kitchin (2014) defende que, no surgimento da era digital, a administração do espaço público passou a ser predominantemente realizada por meio das máquinas, e que o movimento smarter alterou as relações do espaço público com o privado. Kitchin, Lauriault e Mcardle (2016) defendem que esse movimento smarter faz de "inteligente" a palavra da moda, impulsionada por iniciativas de empresas privadas, que "vendem" soluções tecnológicas para os problemas urbanos, transformando os projetos de cidade inteligente em um grande negócio dominado por grandes empresas.

Nesse sentido, o aspecto econômico torna-se relevante na determinação do que passa a ser aceito como inteligente no meio urbano, no qual empresas privadas mercantilizaram serviços públicos e transformaram a promessa da qualidade de vida em promessa de marketing. A cidade inteligente altera a economia do espaço urbano e, concomitantemente, todas as outras facetas da cidade (Pollio, 2016).

A cidade passa a ser um palco de disputas por recursos, universidades de ponta e trabalhadores com alto nível de desempenho em suas áreas, para que possa tornar-se ainda mais forte diante desse cenário. A visão neoliberal da cidade inteligente está relacionada ao desenvolvimento de políticas públicas e ao imaginário do que, de fato, significa uma cidade inteligente (Vanolo, 2014).

Com isso, Vanolo (ibid.) propõe que os projetos de cidades inteligentes tragam novas geometrias de poder e novos discursos. Fazendo uma alusão clara a Rose (1999), para o autor, as novas tecnologias estão cada vez mais conectadas ao desenvolvimento de estratégias políticas com o intuito de controlar a população, a partir de uma relação entre a cidade inteligente e os estudos foucaultianos sobre o poder.

\section{Governamentalidade e relações de poder na cidade}

Governamentalidade e a microfísica do poder são temas associados ao trabalho do filósofo Michel Foucault, sobre o qual centraremos a revisão desses conceitos. 0 poder não é algo tangível e que se possa possuir, mas consiste nas relações e práticas individuais, e Foucault (1983) construiu uma linha analítica com atenção a uma espécie de transição da teoria política tradicional, que tem o foco no poder ao Estado, para uma relação de micropoderes 
individuais que exercem influência na coletividade. Foucault (2014) não estaria interessado em analisar as grandes estruturas, mas em compreender como o poder era exercido nas microrrelações, buscando respostas detalhadas e aprofundadas no cotidiano dos indivíduos.

Para o autor, não existe uma teoria sobre o poder e sim uma analítica do poder, visto que, para se ter uma teoria, seria necessário identificar o lugar de sua origem em um determinado tempo, como um objeto que se manifesta, pois "o poder não se funda de si mesmo, não se dá a partir de si mesmo" (Foucault, 2008, p. 4). Haveria, na realidade, um conjunto de procedimentos e relações por meio dos quais são criados os mecanismos de poder, e esse aspecto é fundamental para o entendimento do papel do poder na construção de arranjos sociotécnicos, como o que será analisado adiante. Assim, para o autor, o poder não é algo natural e sim uma prática, uma relação que é social e historicamente construída.

Para Foucault (ibid.), o poder é a "conduta da conduta". Gordon (1991) ratifica esse pensamento e defende que Foucault trabalha com a noção de que o governo político deveria se preocupar ao mesmo tempo com a totalidade e a individualidade. Para Foucault (1983), o governo de si pode ser associado à conduta como uma forma de moldar as atividades, mas que a arte de governar não poderia ser apropriadamente definida por nenhuma palavra ou expressão francesa, e, para se fazer mais claro, cunhou o neologismo "governamentalidade". A governamentalidade emerge com a separação do governo da pessoa do soberano, que, por meio da razão estatal, impõe uma nova forma de poder mais violento, velado em forma de racionalidade, definindo a ascensão do poder sobre a vida como um problema político e estatal (Candiotto, 2010).

Ao fundir o termo governar (gouverner) com mentalidade (mentalité), Foucault (2008) enfatiza a interdependência entre o exercício de governamento (práticas) e as mentalidades que sustentam tais práticas. Em outras palavras, a governamentalidade pode ser vista como um esforço para criar sujeitos governáveis por meio de controle, normatização e modelagem do poder que é exercido nos sujeitos. Portanto, a governamentalidade é vista como conceito que identifica a relação entre o governamento do Estado (prática) e o governamento do indivíduo (moralidade).

Para deixar mais claro como o autor compreende o termo governamentalidade, é importante enfatizar que ele o divide em três partes interligadas e mútuas (ibid.). A primeira parte diz respeito à formação de instituições, regras, estruturas, cálculos e análises de uma população. Todavia, ele adverte que ela é altamente complexa e envolve o poder do conhecimento de uma população, sendo o conhecimento, político e econômico, e as instituições, mecanismos de tecnologia para coletá-los. A segunda é vista, por ele, como uma linha de frente na qual a governamentalidade consegue compreender todos os tipos de poder, indo além do disciplinar. É necessário esclarecer que, para o autor, o poder em torno do que denomina "governo" não é uma coisa única, e sim uma série de relações com o intuito de gerar poder. Por fim, 0 autor entende a governamentalidade por meio da sua racionalidade estatal da criação de leis e formas administrativas.

Diante disso, o conceito-chave da nova governamentalidade é a razão política da governança, conduzindo esse conceito à formação 
de subjetividade, por meio da formação de sujeitos/cidadãos governáveis e da subjetificação (Foucault, 1991; Rose, 1999; Lemke, 2001). Para Foucault (2008), o Estado moderno nasce à medida que a governamentalidade se torna uma prática política cada vez mais calculada e refletida. Portanto, a governamentalidade não trata da representação da mente individual, e sim de uma coletividade.

Para Vanolo (2014), apesar de o conceito foucaultiano sobre as relações de poder remeter à década de 1980, diversas áreas do conhecimento passaram a aplicá-lo como forma de entender as racionalidades do poder inseridas em contextos mais recentes, como os que envolvem o uso de TICs e a configuração das cidades inteligentes (Luque-Ayala e Marvin, 2015; Krivý, 2018; Klauser, Paasche e Söderström, 2014).

\section{Metodologia: arranjos sociotécnicos e o mapeamento de controvérsias}

\begin{abstract}
A Social Construction of Technology (Scot) é uma teoria que é contrária às ideias deterministas que propõem que a tecnologia por si só constitui o motor da sociedade. 0 desenvolvimento tecnológico é visto como um processo social que sofre alterações pela sociedade, sendo o "sucesso" ou o "insucesso" de uma tecnologia não limitado a uma questão técnica, pois configura um processo de aceitação, conflito e lutas por estabilização.
\end{abstract}

A Scot é uma ferramenta para compreender os caminhos que a tecnologia percorreu: "O desenvolvimento tecnológico deve ser visto como um processo social, não uma ocorrência autônoma"1 (Bijker, 1995, p. 48), e artefatos são influenciados por questões econômicas, culturais, comportamentais e sociais, nas quais estão implícitas as relações de poder e controle.

$\mathrm{Na}$ Scot, as tecnologias são desconstruídas por meio do processo de interpretação e reinterpretação que os grupos sociais relevantes fornecem a elas, mas proporcionando as ferramentas para mapear determinado artefato tecnológico. Para viabilizar esse processo de mapeamento, a Scot apresenta três categorias analíticas: os grupos sociais relevantes (GSRs), a flexibilidade interpretativa (FI) e o fechamento e/ou estabilização, mesmo que esta última não tenha sido utilizada no caso do SwissPass por não configurar um artefato finalizado e aceito em sua forma final de funcionamento.

Na primeira categoria analítica (GSR), procura-se identificar todos os membros que fazem parte de um mesmo grupo, para que se possa proceder a construção de mapas de atores, interesses, relações de aliança e conflito, etc. No presente caso, os GSRs identificados concentram-se em torno da tecnologia inteligente com foco em mobilidade, e foram levantados quais grupos têm mais influência ou poder sobre os demais.

0 segundo conceito (FI) está intimamente relacionado aos GSRs, pois refletem suas interpretações do artefato em desenvolvimento, de acordo com seus próprios interesses e visões de mundo. Howcroft e Light (2010) afirmam que a flexibilidade interpretativa é um conceito muito útil para entender como os GSRs compreendem um determinado artefato tecnológico. Nesse sentido, entende-se que a flexibilidade interpretativa está relacionada à 
forma como determinado grupo relaciona-se com a tecnologia e a como mesmo artefato tecnológico pode ter diversas interpretações. É, por meio dessas significações da Fl, que as tensões entre os grupos se tornam evidentes e o poder se faz visto. Vale salientar que a FI não constitui uma ferramenta para o mapeamento das controvérsias, e sim um caminho em que essas tensões ocorrem.

A cartografia das controvérsias é parte integrante da Teoria Ator Rede (TR), desenvolvida por Bruno Latour (2005). Segundo ele, uma controvérsia representa um dilema, um conflito, um desentendimento, um problema a ser resolvido, geralmente na disputa entre mais de um GSR e pautado pela variabilidade de interesses envolvidos, expressos pela $\mathrm{Fl}$.

Venturini (2009) defende que a cartografia das controvérsias e a construção do mapeamento são técnicas de investigação que giram em torno dos problemas tecnológicos, mas não são exclusivas a ele. As controvérsias têm sido o foco de muitos trabalhos com base na STS, entre eles os que atuam com a Scot e a TAR. Para Marres e Rogers (2005), essa técnica auxilia na identificação do caminho que a tecnologia percorre.

Venturini et al. (2015) argumentam que o mapeamento de controvérsias visa facilitar a compreensão das complexidades que envolvem diversas plataformas, especialmente as tecnológicas, tornando os conflitos sociotécnicos mais visíveis por meio de mapas.

A pesquisa empírica de caráter qualitativo, e que tem como objeto de pesquisa o projeto de cartão inteligente de mobilidade, SwissPass, foi realizada in loco, entre os meses de fevereiro e julho de 2017, e caracterizou-se como um estudo de caso único seguindo as recomendações de Yin (1994). 0 autor afirma que uma investigação que se caracteriza como um estudo de caso, seja ele único ou múltiplo, "[...] surge do desejo de compreender fenômenos sociais complexos" e "[...] retém as características significativas e holísticas de eventos da vida real" (p. 14).

A Suíça vem, há alguns anos, investindo em multimodais de transporte público com 0 intuito de minimizar os congestionamentos de suas cidades, causados pelo uso intenso de automóveis. Diante desse cenário, em 2011, o Governo Federal lançou uma chamada pública para a apresentação de projetos com uso de tecnologias no espaço urbano. Em 2013, o projeto foi iniciado e em agosto de 20150 SwissPass foi lançado como um sistema nacional de mobilidade, indexando 7 modais de mobilidade (ônibus, trem, metrô, barco, bicicleta, carro compartilhado e esqui). Portanto, a escoIha do estudo de caso foi baseada no ineditismo e no impacto do sistema no espaço urbano. O SwissPass é inédito na sua implantação nacional e multimodal de mobilidade, por integrar todo o espaço urbano de um país em torno de um sistema (ao contrário de outros esquemas com cartões inteligentes de mobilidade).

Nesse contexto, dividiu-se o trabalho em estudo documental e entrevistas com atores representativos dos principais GSRs (Figura 1), identificados em fases distintas: a partir da primeira aproximação com o caso, por meio de matérias da imprensa, alguns documentos oficiais e pesquisas científicas já realizadas sobre o projeto; e, num segundo momento, pelo contato com os entrevistados levantados inicialmente, a partir dos quais se identificaram outros atores, no procedimento conhecido como "bola de neve". 
Seguindo está técnica, as entrevistas foram realizadas em francês e inglês, com duração média 30 minutos, com perguntas semiestruturadas enviadas previamente para os entrevistados. Eles ocupavam cargos gerenciais, alguns deles executivos, proporcionando maior validade aos dados - além de o país apresentar uma forte transparência de seus dados documentais, que corroboraram e complementaram as entrevistas. Os entrevistados foram selecionados com base no GRS relacionado ao SwissPass.

A coleta documental envolveu os seguintes elementos relacionados ao SwissPass:

a) lei sobre proteção de dados;

b) relatórios sobre os benefícios e riscos do SwissPass;

c) documentos oficiais sobre sua aplicabilidade; d) sumário de uma pesquisa oficial sobre 0 SwissPass e informações cedidas pelo Swiss Federal Railway (SBB).

Com o intuito de dar mais validade aos documentos, a coleta dos dados documentais foi feita com base em sites federais, de empresas cantonais e escritórios federais, tais como: o da União de Transporte Público (Voev), o da SBB, o do Transporte Público de Genebra (TPG), o do escritório de transparência de dados e privacidade, entre outros. As informações obtidas objetivaram evidenciar os grupos sociais relevantes, as controvérsias em relação ao caso e suas disputas de poder mais evidentes.

A coleta dos dados midiáticos foi realizada por meio de um banco de dados nacional que coleta, classifica e arquiva todo o material midiático suíço, chamado EuroPress.ch. Foram utilizadas as seguintes palavras-chave: "SwissPass" + (and) "mobilidade inteligente"; "mobilidade inteligente"; "mobilidade inteligente" + (and) "unificação do sistema"; " cartão de identidade em mobilidade" + (and) "SwissPass" "SwissPass" + (and) "mobilidade inteligente", não se restringindo ao jornal em que estava sendo veiculada a notícia. Esse banco de dados foi inicialmente acessado pela biblioteca central localizada na capital (Berna) e, em seguida, por meio de um acesso remoto, fornecido pela própria biblioteca, à Escola Politécnica Federal de Lausanne (EPFL) - local da pesquisa in loco. Também foi realizada a busca por trabalhos acadêmicos sobre a temática no diretório das teses de dissertação da biblioteca virtual do EPFL.

A construção do corpus dessa pesquisa teve como base sua pergunta norteadora. Optou-se por seguir as recomendações de Bauer e Aarts (2002). Para os autores, um dado homogêneo não significa a mesma quantidade numérica, e sim a mesma fonte de informação, no caso da pesquisa, textos midiáticos, documentais e das transcrições das entrevistas.

Na Figura 1 segue a demonstração visual do corpus da pesquisa.

\section{SwissPass: poder e controvérsias na unificação do transporte público}

0 caso do SwissPass torna-se emblemático no campo da mobilidade pelo pioneirismo na tentativa de unificação de serviços em nível nacional, a partir da implantação de um cartão único inteligente com a intenção de integrar todos os sistemas de transporte do país. É a primeira vez no mundo que um país unifica 
Figura 1 - Corpus da pesquisa

\section{Fontes Orais}

\section{5 entrevistas}

Fontes Documentais
79 reportagens da mídia

10 artigos científicos

71 documentos oficiais

2 Leis

6 Projetos

16 Relatórios

46 Dados públicos do SwissPass
Fonte: Elaboração própria.

todos os modais e todas as empresas de mobilidade por meio de uma tecnologia (cartão de identidade da mobilidade).

A consolidação de um único cartão de identidade em um país inteiro envolve procedimentos complexos do ponto de vista administrativo, técnico, político, econômico e cultural. Mesmo em um território pequeno, existem muitos atores envolvidos nesse processo. A linha do tempo (Figura 2) evidencia que já existia uma proposta de cartão desde 1989, antes da popularização da internet ou do GPS, o que confirma a busca histórica constante pela unificação da mobilidade no país, com foco no transporte público.

0 SwissPass é unificado a partir dos seguintes modais de mobilidade: a) trens; b) metrô; c) ônibus; d) barco; e) bicicleta; f) barro compartilhado; g) esqui.
0 sistema contava, em 2017, com mais de 2,2 milhões de usuários, e o objetivo das autoridades é atingir toda a população que utiliza o transporte público na Suíça. 0 sistema integrado conta com 415 empresas ligadas a todos os modais de transporte, sendo 240 apenas de ônibus, metrô e trem. 0 sistema todo é composto por mais de 28 mil quilômetros de ferroviais, com 869 rotas de ônibus, e permite o movimento de mais de 1,5 milhão de passageiros por dia no país, além de ter pontualidade de $87,8 \%$ nos modais de transporte (Swisstravel, 2017).

Além disso, o SwissPass também está associado a museus nacionais, redes de hotéis e à biblioteca nacional. 0 cartão possui as seguintes segmentações: passe geral (general abonemment): oferece ao consumidor acesso a todos os modais descritos acima, com 
Figura 2 - Linha do tempo - SwissPass

1902 Criada a Swiss Federal Railway Chemins de fer fédéraux suisses (CFF) Schweizerische Bundesbahnen (SBB)

Ferrovie federali svizzere (FFS)

Criado o Passe Geral (Generel Abonemment GA)

1906 Primeiro ônibus em circulação

1945 Fim da Segunda Guerra Mundial

1960 Crise no Transporte Público Suíço

1971 Introdução do cronograma de intervalo entre os trens

1982 Pontualidade de $82 \%$ da frota na suíça

1989 Lançada a primeira versão do SwissPass

1990 Uso comercial da Internet

Uso comercial do GPS

1998 Criado o escritório federal de rodovias

Criado o escritório federal de transportes

2000 Implantação do projeto Rail 2000 (projeto de modernização da mobilidade)

2008 IBM lança campanha mundial Smarter Planet

2013 Iniciada a fase de desenvolvimento do SwissPass

2015 Lançado o SwissPass

2017 SwissPass estabelece relação com o conceito de smartmobility

SwissPass se ramifica e cria SwissGreenPass

utilização ilimitada e duração de, no mínimo, quatro meses; meia tarifa: quando o consumidor faz poucas viagens e utiliza pouco 0 transporte público, o sistema oferece desconto de $50 \%$ quando há necessidade de comprar um trecho específico; modular. nessa opção, o consumidor pode informar quais modais de transporte vai utilizar; ponto a ponto: é quando o consumidor só utiliza o SwissPass para ir de um lugar ao outro de forma fixa; regional: quando o consumidor adquire o passe de acordo com a região do país (SBB, 2017). 
0 cartão também é dividido em categorias: adultos: homens (entre 25 e 65 anos) e mulheres (entre 25 e 64 anos); crianças: entre 6 e 16 anos (com redução do preço); jovens: entre 16 e 25 anos; estudantes: entre 25 e 30 anos, matriculados em uma universidade da Suíça (com redução de preço); idosos: a partir do aniversário de 64 para mulheres e 65 para homens; para casados: para casais em que um dos parceiros tem o cartão, o(a) companheiro(a) tem desconto; deficientes: pessoas com qualquer tipo de redução de mobilidade; família: oferece desconto se todos os membros da família tiverem o cartão; cachorro: os cachorros de médio porte precisam pagar passagem e podem ter seu próprio SwissPass (SBB, General Aabonement, 2017).

Apesar de todos os benefícios aparentes que o sistema de mobilidade inteligente possa ter proporcionado à sociedade suíça e ao meio urbano, ele não foi implantado e estabilizado sem disputas claras de poder e muitas controvérsias. Antes, a identificação dos GSRs e o mapeamento da FI auxiliam na compreensão dessa complexidade envolvida no processo de criação e implantação do SwissPass.

0 primeiro e mais evidente ator, destacado nas buscas documentais iniciais, foi a Swiss Federal Railway (SBB), por ser o principal órgão responsável pela implementação do sistema, detendo $70 \%$ do mercado de mobilidade na Suíça. Foi, portanto, o primeiro GSR identificado. A SBB negociou com as 240 empresas envolvidas diretamente com o SwissPass.

Bijker (1995) defende que seguir os atores é algo muito mais profundo do que a mera identificação dos envolvidos em torno de um artefato, o que ficou claro com a análise desse primeiro grupo. Pinch e Bijker (1984) entendem que um grupo social pode ser uma organização com diversos grupos ou apenas um indivíduo.

Visto que a SBB é composta por diversos departamentos e quase todos foram envolvidos no processo de criação e implantação do SwissPass, caracterizou-se um grupo ao mesmo tempo homogêneo (quanto ao significado do SwissPass) e heterogêneo (quanto às funções e disposições).

0 segundo GSR encontra-se menos exposto e é composto pelas três maiores empresas públicas de mobilidade depois da SBB, que são a BLS (Bern-Lotschberg-Simplon), Postauto e ZVV (Zürcher Verkehrsverbund). Essas três empresas têm uma posição historicamente contrária aos projetos da SBB, e estão localizadas na parte alemã da Suíça. Discordam em relação à distribuição do mercado suíço de mobilidade e, por isso, representam o grupo que atuou mais fortemente contra a implantação do projeto.

0 terceiro grupo foi estabelecido pela TPG (Transports Publics Genevois), TL (Transport Lausanne) e Unireso, que também são empresas públicas. Essas empresas estão localizadas na Suiça francesa e têm uma posição intermediária em relação à SBB, sendo as primeiras empresas escolhidas para implantar toda a plataforma do SwissPass.

0 quarto grupo foi composto pelos sindicatos dos motoristas e trabalhadores na fiscalização da mobilidade, que apresentam uma visão crítica sobre o SwissPass, mas sem poder político suficiente para atuar contra a implantação do passe. 0 sindicato dos consumidores não quis se envolver no processo, por uma pressão legal que impõe aos sindicatos distância das decisões públicas na Suíça. Esse fato 
será melhor detalhado no decorrer das análises das controvérsias.

0 quinto e último grupo foi o escritório de proteção de dados, que mantém uma relação cordial com a SBB, mas que impôs diversas condições ao projeto do SwissPass.

Outras empresas menores não chegaram a se organizar nem contra, nem a favor do SwissPass. Por vezes, isso se deu ao seu tamanho e participação no mercado ou por não quererem se envolver, simplesmente. Portanto, elas não foram consideradas um GSR para a pesquisa proposta, visto que Pinch e Bijker (ibid.) defendem que um GSR tem como requisito fundamental estar envolvido no processo do artefato em questão. Para Bijker (1995), os GSRs precisam - de alguma forma e em diferentes proporções - dar significado a esse artefato.
A próxima etapa envolve a constituição dos elementos para o mapeamento das controvérsias. Para tanto, foi utilizada uma série de ferramentas analíticas fornecidas por Venturini (2012), divididas nas perguntas de base "o quê", "quem", "como", "onde" e "quando" (Figura 3).

Para o autor, nenhuma controvérsia está isolada das demandas da sociedade, sejam elas de qualquer ordem. No caso do SwissPass, o que está relacionado aos seguintes pontos:

- Poder público: empresa federal de mobilidade; escritório federal de proteção dos dados; escritório federal de transporte; escritório federal de inovação e pesquisa; escritório federal de rodovias; escritório federal de meio ambiente; empresas cantonais de mobilidade; projetos públicos de inovação em mobilidade (EPFL e Universidade Politécnica Federal de Zurich ETHZ); prefeituras municipais.

Figura 3 - Caminho das controvérsias do SwissPass

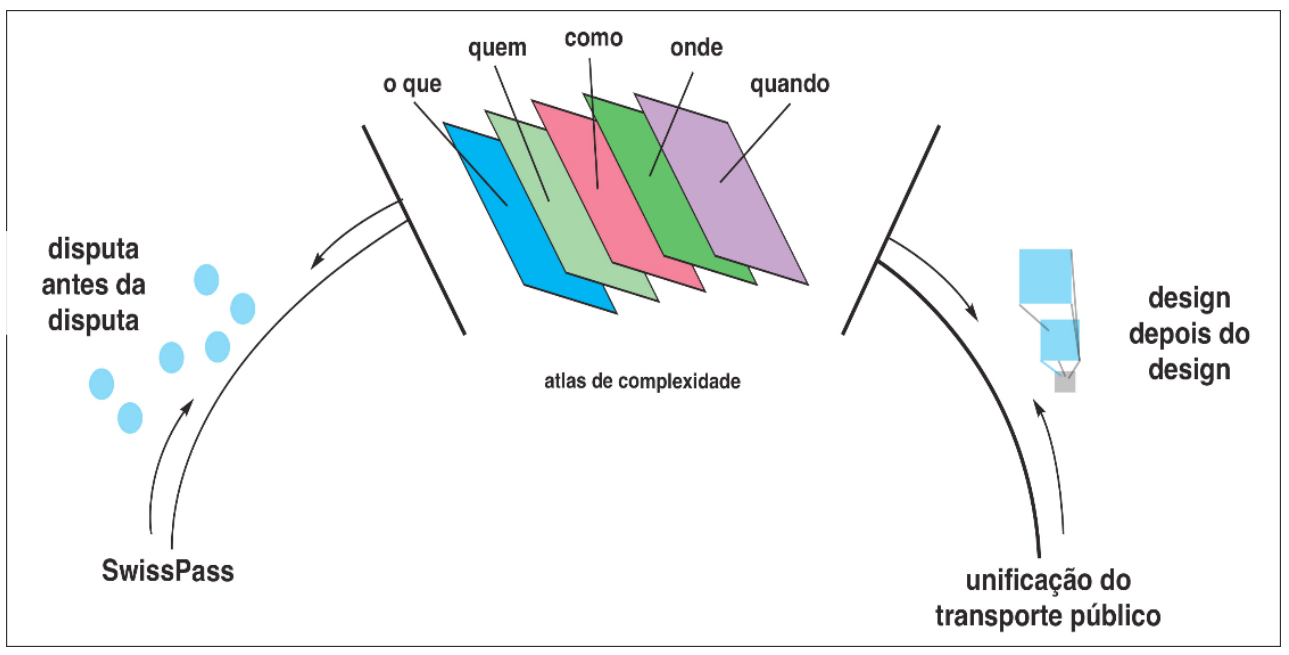


- Infraestrutura de software: ampliação do banco de dados e do uso da internet na mobilidade pública.

- Plataforma Nova: unificação de todas as plataformas de dados do cidadão para a viabilidade do SwissPass.

- Inovação em mobilidade: projetos públicos com incentivo do Fundo Nacional de Pesquisa e projetos privados com incentivo de empresas privadas, ambos com foco em mobilidade inteligente.

- Treinamento dos funcionários para lidar com o SwissPass: a mudança do sistema obrigou as empresas a treinarem funcionários, que somam mais de 59 mil.

- Economia: estabilidade econômica e da moeda, que favorece um ambiente mais seguro para a inovação na mobilidade urbana;
- Impactos desta mudança no comportamento do consumidor: não foram feitos estudos prévios sobre o impacto do SwissPass no comportamento do consumidor diante dessa mudança, mas houve resistência dos consumidores mais antigos.

Os elementos quem e como reforçam que as controvérsias não são acontecimentos isolados e que estão presentes nas relações entre os grupos sociais relevantes. A pesquisa contempla cinco GSRs, tendo suas identidades definidas, assim como seus respectivos posicionamentos em relação ao caso, como mostra a Figura 4.

A Figura 4 demonstra as relações que formam as identidades dos atores e compõem as controvérsias, que nem sempre são harmônicas à SBB, o maior grupo, que tem relações

Figura 4 - Relação conflitante e não conflitante entre os atores

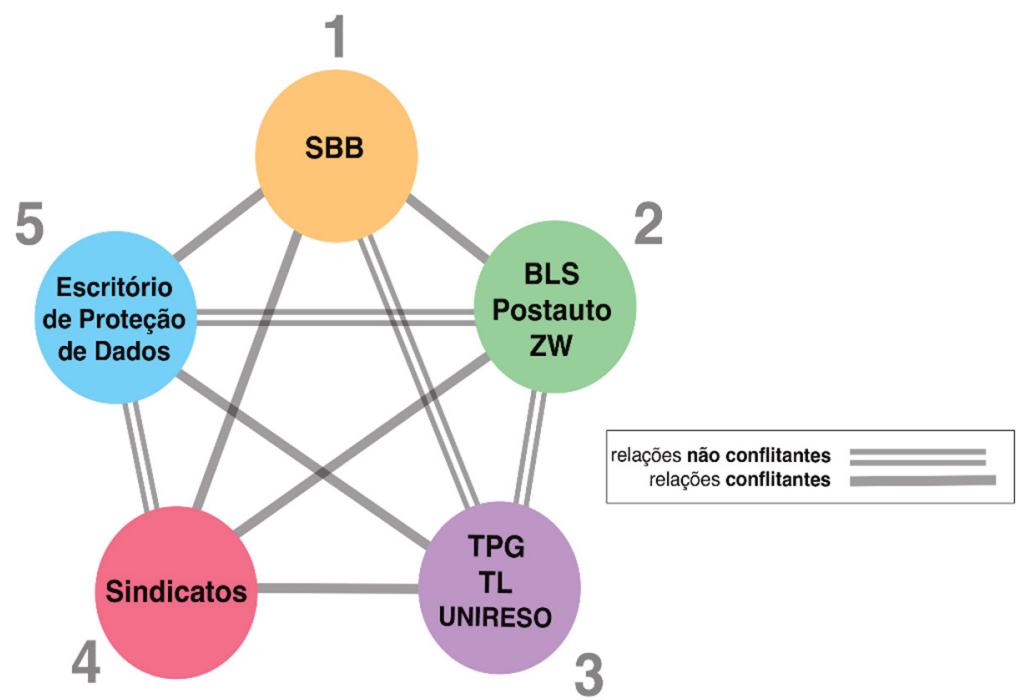

Fonte: elaboração própria. 
conflitantes com quase todos os outros atores. Isso ocorre porque a SBB detém a maior fatia do mercado, sendo a responsável pelo projeto e implantação. Ela precisou convencer os demais a aceitarem o SwissPass, e essa negociação envolveu complexas estratégias de convencimento. Sua relação com o terceiro grupo, por sua vez, é estável e permite a formação de alianças. Outro destaque é o grupo dos sindicatos, que, além de ter conflitos com a SBB, não possui muita força política. Esse caso é bem particular na Suíça, visto que no país os sindicatos não têm um forte peso decisório, tornando sua posição ainda mais frágil e delicada.

0 grupo composto pelo SBB, como fica claro na Figura 4, tem mais relações conflitantes do que harmônicas, e isto se deu por três razões centrais. A primeira é a empresa pública com maior controle de mercado, então qualquer projeto que ele desenvolva as outras empresas não aceitam bem e tentam, na negociação, diminuir o poder da SBB, a exemplo do que ocorreu com o SwissPass. Segundo, o SBB elabora os projetos utilizando seus departamentos e com foco nas suas necessidades; as outras empresas só são integradas ao projeto quando ele já tem um escopo elaborado, causando, com isso, problemas de aceitação dos projetos por outras empresas que não são integradas no processo de elaboração. Terceiro, por se tratar de uma empresa pública de mobilidade e não precisar de aprovação por plebiscito da população, os escritórios de controle, como o de proteção de dados e transparência, são muito mais rígidos com a SBB do que em projetos que já passam por uma aprovação pública.

0 único grupo que é declaradamente favorável a todos os projetos da SBB é composto pela TL, TPG e Unireso, que são localizados na parte francesa da Suíça, conhecida como Suíça Romande, também por uma questão histórica da época da unificação da suíça como um único país.

O grupo composto pelo escritório federal de proteção de dados e transparência também se apresentou como destaque, por ter sido o escritório responsável por avaliar o sistema. Como mencionado, o SwissPass não foi pautado por um plebiscito e foi, portanto, avaliado exclusivamente pelos órgãos federais suíços. Nesse sentido, o escritório em questão opôs-se ao sistema por considerá-lo uma violação ao direito à privacidade, visto que, com o uso da plataforma Nova, todos os dados dos cidadãos estariam disponíveis para as empresas públicas de mobilidade. Diante desse possível risco do uso indevido dos dados e quiçá da sua venda, 0 escritório federal de proteção de dados e transparência, por meio de uma lei federal, impôs à empresa operadora do sistema - SBB - que os dados dos usuários fossem destruídos em no máximo 90 dias. Este passou a ser, assim, um dos principais impasses para a implantação do sistema em todo o território nacional.

Outro impasse se deu com o grupo formado por BLS, ZW e Postauto, empresas localizadas na parte alemã da suiça. Por uma questão igualmente histórica, esse grupo faz oposição a quase todos os projetos do SBB, por considerar que a empresa pública detém uma fatia muito grande do mercado de mobilidade. No caso específico do SwissPass, esse grupo tentou negociar para que o SBB (com 70\% do mercado) cedesse $5 \%$ para as empresas da parte alemã, tendo, como contrapartida, uma aceitação facilitada do sistema nessa região do país. Com a rejeição da proposta, por parte do 
SBB, o grupo impôs que o SwissPass só fosse implantado na região após testes provando que não traria nenhum problema ou risco aos seus cidadãos.

Com isso, o sistema tornou-se nacional em suas ferrovias - controladas pelo SBB -, mas regional no espaço urbano, implantado em sua integridade apenas na região Romande, que tem como destaque as empresas TPG, TL e Unireso, empresas parceiras do SBB. Diante desse impasse, o SBB escolheu manter o discurso de que o SwissPass era nacional, quando, de fato, era aceito em todo território, mas não estava sendo utilizado na região alemã do país. Tais conflitos e impasses demostram uma intensa disputa de poder em torno do artefato urbano de mobilidade inteligente, reforçando os argumentos de Foucault (2008) que defende que as lutas e as disputas por poder são social e historicamente construídas.

Sobre o elemento onde, Venturini et al. (2015) argumentam que toda controvérsia sempre faz parte de uma metacontrovérsia e que esta é sempre composta por diversas subcontrovérsias. Por meio dessa técnica, os autores defendem que os pesquisadores ou cartógrafos devem poder escolher o nível da sua análise, mas alertam para que estes não fiquem em áreas muito superficiais e cheguem às disputas, associando essa declaração aos preceitos foucaultianos, apresentados anteriormente. As disputas são vistas por Foucault (2000) como pequenas guerras, nas quais todos os mecanismos de poder ficam mais evidentes. Ratificando esse argumento, Venturini et al. (2015) defendem que as controvérsias, apesar de muitas vezes refletirem embates técnicos, estão em um campo de batalhas em que existem visões de mundo conflitantes. Assim, é necessário detalhar as controvérsias para demonstração do elemento onde.

A Figura 5 evidencia o SwissPass como metacontrovérsia, estando as macrocontrovérsias relacionadas a aspectos gerais de formação de uma política pública abrangente como esta, em um nível em que não se podem constatar especificidades do caso em pauta e, portanto, sem revelar nuanças relevantes das disputas de poder. É, assim, nas subcontrovérsias e nas suas categorias que as disputas estão mais claras e evidentes.

Apesar de o sistema ser apenas um cartão vermelho que conduz as pessoas de um ponto o outro no país, há, por trás desse pequeno objeto de plástico, uma série de relações de poder e controvérsias

Como está demonstrado na Figura 5, são muitas as disputas que compõem a história sociotécnica dessa tecnologia de transporte. Apesar do sistema utilizar tecnologias inteligentes, não foi classificado pela SBB como uma mobilidade inteligente e, sim, como a mobilidade do futuro da Suíça, como um sinônimo para inteligente. Nesse sentido, Elliott e Urry (2010) defendem que, com a inserção de novas tecnologias, a mobilidade passou a ser um campo complexo e repleto de relações de poder, em que o termo "mobilidade inteligente" ou smart passou a significar uma sofisticação das relações entre os objetos, a internet e as pessoas. A mobilidade é agora relacionada a conexão, internet, aplicativos, plataformas e bancos de dados em que o mais importante é codificar e identificar os fluxos móveis de pessoas tanto no mundo virtual quanto no físico. Flugger (2017) defende que a mobilidade inteligente torna os sistemas de mobilidade mais velozes, adaptáveis e híbridos, em que a informação e 
Figura 5 - Mapa das Controvérsias do SwissPass

\begin{tabular}{|c|c|c|}
\hline \multirow{22}{*}{$\begin{array}{c}\text { macro } \\
\text { controvérsias }\end{array}$} & \multirow{4}{*}{ sociedade } & governo \\
\hline & & consumidores \\
\hline & & legislação \\
\hline & & comunidade científica \\
\hline & \multirow{4}{*}{ infraestrutura tecnológica } & crise no sistema \\
\hline & & novas tecnologias \\
\hline & & modais \\
\hline & & público $\mathrm{x}$ privado \\
\hline & \multirow{5}{*}{ pesquisa em inovação } & incentivo à pesquisa \\
\hline & & incentivo à inovação \\
\hline & & fundos nacionais \\
\hline & & fundos privados \\
\hline & & liberdade \\
\hline & \multirow{2}{*}{ impacto } & segurança \\
\hline & & privacidade \\
\hline & \multirow{2}{*}{ economia } & estabilidade \\
\hline & & crescimento \\
\hline & \multirow{2}{*}{ meio ambiente } & ecologia \\
\hline & & qualidade do ar \\
\hline & \multirow{3}{*}{ poder } & disputas \\
\hline & & conflitos \\
\hline & & divergência do discurso \\
\hline \multirow{26}{*}{$\begin{array}{c}\text { sub } \\
\text { controvérsias }\end{array}$} & \multirow{6}{*}{ integração das empresas } & unificação \\
\hline & & modificação do trabalho \\
\hline & & transparência \\
\hline & & abertura dos dados \\
\hline & & marketing \\
\hline & & controle \\
\hline & \multirow{6}{*}{ impacto } & riscos \\
\hline & & segurança \\
\hline & & aumento do consumo \\
\hline & & consumidor fiscal \\
\hline & & corte de estações \\
\hline & & aumento de estações \\
\hline & \multirow{4}{*}{ cidadão consumidor } & inclusão obrigatória \\
\hline & & sistema autônomo \\
\hline & & ausência de plebiscito \\
\hline & & ausência de pesuisa \\
\hline & \multirow{4}{*}{ privacidade } & big data \\
\hline & & internet das coisas \\
\hline & & vigilância \\
\hline & & monitoramento \\
\hline & \multirow{3}{*}{ processo } & aumento dos consumidores \\
\hline & & alteração do trabalho \\
\hline & & alteração no uso dos dados \\
\hline & \multirow{3}{*}{ infraestrutura tecnológica } & NOVA plataforma \\
\hline & & QI code \\
\hline & & RFID \\
\hline
\end{tabular}

Fonte: elaboração própria. 
o poder se tornam elementos comuns. De fato, o sistema enquadra-se no que Eliott e Urry (2010) e Flugger (2017) defendem como mobilidade inteligente, visto que todos os dados estão em uma única plataforma chamada Nova, os leitores dos cartões são conectados à internet e lidos por meio de aplicativos.

Apesar desse destaque, alguns discursos e apontamentos são capazes de abrir novos campos de exploração teórica. Por exemplo, a subcontrovérsia da privacidade, que coloca a possibilidade de estudos sobre liberdade, direitos dos cidadãos e direito das empresas públicas. Mesmo não sendo a privacidade tema central deste artigo, diversos fatores passaram a estar relacionados a ela, visto que 0 SwissPass é um sistema coletor de dados que vão para um sistema analisado por meio do Big Data; portanto, as questões da privacidade não poderiam deixar de ser consideradas, por se tratar de um mecanismo de segurança defendido por Foucault (2008), fornecendo os dados da população indispensáveis para que a biopolítica seja exercida. Apresentou-se, como um dos principais impasses, a implantação do sistema no espaço urbano.

Outra dessas possibilidades diz respeito à subcontrovérsia dos processos, que envolveria trabalhar detalhes das especificidades técnicas do artefato, as controvérsias em torno da escolha tecnológica atualmente aplicada, etc.

0 fator da vigilância, entretanto, ganha significância por se tratar de um mecanismo de segurança descrito por Foucault (ibid.), fornecendo os dados da população indispensáveis para que a biopolítica seja exercida. A materialização da preocupação com as possíveis relações entre vigilância e poder nas políticas de transporte, por parte do governo federal suíço está exposta na Figura 6, na descrição de um sistema de supervisão de segurança por parte da autoridade federal de transportes (Federal Office of Transport - FOT). O SwissPass não é citado como parte do sistema, mas seu potencial invasivo e de monitoramento faz-se representar no esquema, pelo fato de compor um dispositivo de coleta, organização e integração de dados pessoais cadastrais georeferenciados dos cidadãos ou portadores do cartão.

Assim, tanto o governo federal quanto a SBB têm o poder sobre os dados da população. Este é também um ambiente altamente tecnológico, em que tecnologias inteligentes interagem com plataformas igualmente inteligentes com o intuito de controlar a "bio" da população - ou seja, a vida. Desse modo, a vida passa a ser permeada por biopoderes cibernéticos e ciborgues, a cargo de empresas privadas e governamentais que detêm o poder da informação eletrônica dos cidadãos. Essa perspectiva valida o entendimento de Hardt e Negri (2009) quanto à defesa de uma evolução nos estudos de Foucault, de que o biopoder atual está relacionado às tecnologias e produz novas formas de vida.

No caso do SwissPass, os mecanismos de segurança estão inseridos nele de forma velada. 0 poder dos dados fornecidos por esse artefato inteligente demonstrou ser difundido como algo unicamente benéfico ao cidadão-consumidor. 0 SwissPass também pode ser associado ao conceito de Foucault (1983) da conduta-da-conduta, em que o governo político trabalha com a noção da totalidade por meio da individualidade. 0 poder reafirma-se no momento em que esse governo consegue moldar as atividades dos cidadãos. No caso do SwissPass, o governo político é o federal. 
Figura 6 - Safety Supervision System

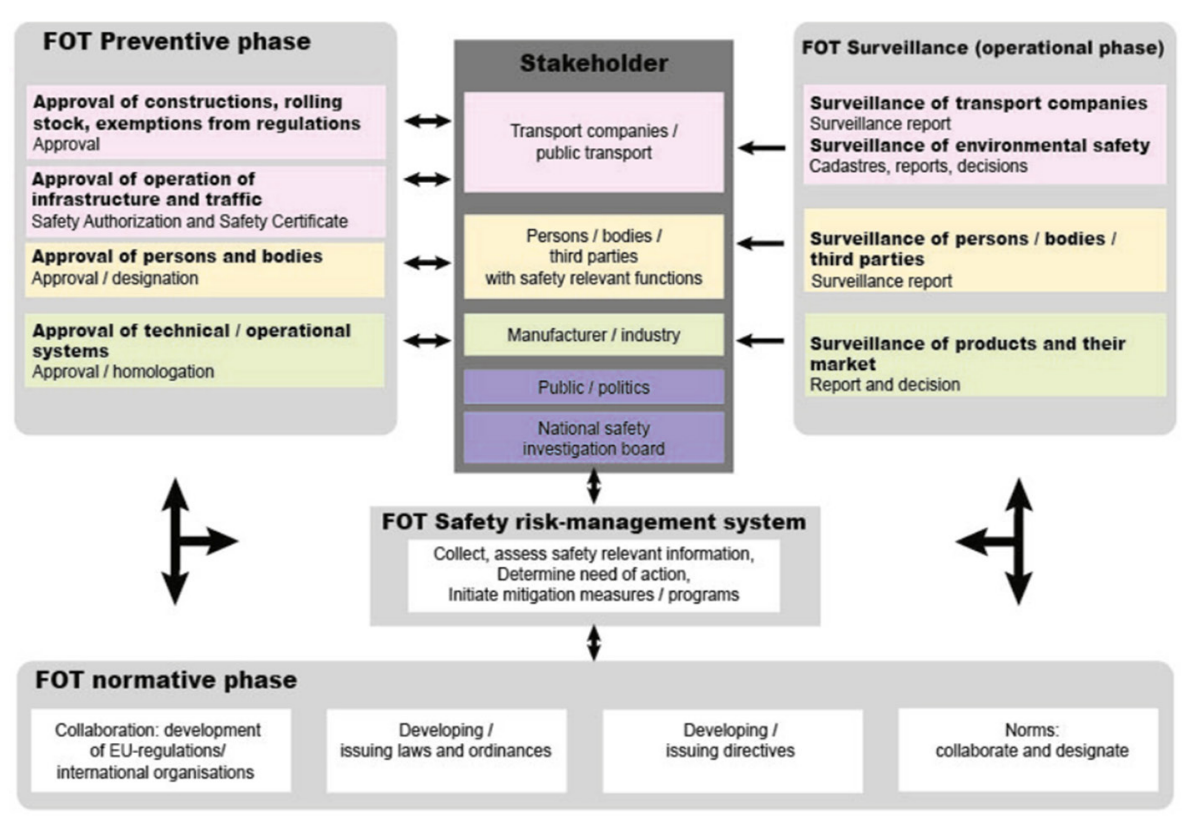

Fonte: FOT (2017).

Da análise documental e do discurso nas entrevistas, ganha importância uma estratégia de fechamento e estabilização do artefato tecnológico SwissPass por parte dos atores protagonistas, o que proporciona um ofuscamento sobre a percepção das inúmeras controvérsias criadas pelo caso. Ou seja, apesar da vasta lista de macro e subcontrovérsias, as disputas entre os GSRs mais importantes concentraram o discurso de convencimento por meio da imprensa nos potenciais benefícios de gestão e na "grande" inovação tecnológica alavancada pelo sistema unificado de transporte. Do ponto de vista tecnológico, o SwissPass não representa um grande avanço em inovação, visto que outros sistemas semelhantes já haviam sido criados em outras cidades europeias e norte-americanas (ex.: Oyster Card, em Londres). A inovação constitui-se no fato de ser utilizado por todos os modais de transporte de um país inteiro, isto é, a inovação está presente na política pública e em seus desdobramentos, e não no artefato técnico. Essas diferenças não são anunciadas abertamente nos documentos ou na imprensa, depositando no discurso em prol do SwissPass um aspecto de marketing em inovação tecnológica, com forte apelo à população.

Um aspecto relevante no processo de consolidação desse artefato foi a utilização do conceito de inteligenciamento de dados 
para o espaço urbano, assemelhando-se à definição de urbanismo inteligente fornecida por Luque-Ayala e Marvin (2015). Para os autores, por meio do urbanismo inteligente, as infraestruturas urbanas passaram a ser relacionadas ao uso de tecnologias digitais. Segundo eles, o conceito de urbanismo inteligente e sua aplicação no espaço urbano são compostos por uma ênfase no sistema tecnológico e um processo em que se desconsideram as relações políticas e sociais. 0 SwissPass seguiu claramente essa linha em que o poder decisório não estava relacionado aos possíveis impactos ou riscos ao meio urbano, político ou social e sim focado em uma racionalidade tecnológica e neoliberal de gestão de dados e de negócios.

Como mencionado, o SwissPass não passou por um plebiscito, um fator interessante, visto que, apesar de a Suíça ser mundialmente conhecida por seus plebiscitos e pela consulta popular, nem todos os temas são levados ao debate. 0 governo federal possui uma lista de questões que os cidadãos não escolhem, tampouco opinam. Entre eles, estão a segurança, a energia e a mobilidade. Por tal motivo, o SwissPass só se tornou de conhecimento da população poucos meses antes de sua implantação, o que causou uma forte rejeição ao projeto por parte da mídia e do grupo dos sindicatos, mas não dos cidadãos. Especialmente os cidadãos mais jovens não se opuseram ao sistema por ver nele um movimento do governo federal em manter o país como exemplo de eficiência, pontualidade e organização urbana. Apesar de uma oposição da mídia e dos sindicatos, a implantação do SwissPass fez com que as empresas públicas de mobilidade, que vinham apresentado déficit devido ao incentivo do transporte individual, a exemplo do que vem acontecendo em todo o mundo, revertessem parcialmente essa lógica. Com a implantação do SwissPass, o sistema ampliou as possibilidades de os cidadãos usarem o transporte coletivo em todo o país, ampliando também o interesse de pesquisadores, ativistas da mobilidade e outros governos em estudarem esse sistema.

\section{Conclusão}

Segundo Luque-Ayala, Mcfarlane e Marvin (2016), o espaço urbano vem se transformando em uma mistura de novas tecnologias e infraestruturas, provendo mais flexibilidade e respostas rápidas aos problemas urbanos, do ponto de vista da gestão. Os autores igualmente advertem sobre o foco exagerado no uso intenso de tecnologias digitais, plataformas e utilização de dados como soluções imediatas para problemas urbanos de ordem social, política e econômica. Kitchin, Lauriault e Mcardle (2016) argumentam que o uso de novas tecnologias no espaço urbano provoca o surgimento de uma nova retórica urbana; a relação "saber-poder" defendida por Foucault (2008), que proporciona uma visão sobre o exercício do poder na sociedade atual, em que dispositivos de coleta de dados se tornam cada vez mais comuns.

Este estudo, portanto, visou enaltecer discussões presentes nesse contexto, dando ênfase às modificações causadas pelas relações de poder no âmbito das infraestruturas urbanas, a partir da caracterização de um artefato tecnológico de mobilidade urbana implantado na Suíça, conhecido como SwissPass. A pesquisa focou na construção histórica e sociotécnica desse sistema, com ênfase no mapeamento 
de vários níveis de controvérsias operadas por grupos sociais relevantes identificados como protagonistas nesse processo de construção e pautados por certos níveis de relação de poder segundo seus próprios interesses e visões sobre a nova tecnologia e a política proposta.

Buscou-se, por meio deste estudo, analisar o contexto pelo qual as relações de poder se formam e estabelecem ligações nessa realidade. Observou-se que o sistema instalado em todo o país apresentou uma série de controvérsias, e que seu detalhamento poderia abrir novas e interessantes frentes de estudo para entendimento da microfísica de poder em cada uma das subcontrovérsias mapeadas. Apesar de a implantação do SwissPass ter sido uma "imposição" de alguns grupos sociais relevantes - especificamente a união do SBB com o grupo social formado pela TPG, TL e Unireso, que se beneficiaram diretamente desse sistema -, não houve um forte movimento contrário ao projeto. Esse fato pode ser explicado pela criação de uma mentalidade coletiva em torno do projeto, destacando-se os benefícios para os cidadãos, enaltecidos pela visão de que se trata de um sistema inovador que, portanto, mantém o país como um exemplo de excelência na mobilidade urbana, tendo o discurso da inovação como principal tática de convencimento por parte dos GSRs mais interessados na nova política.

Para Foucault (2014), as racionalidades são criadas por meio do que ele chamou de política da verdade, em que se estabelece o discurso na construção coletiva da "verdade". Segundo o autor, a verdade é uma forma de imposição e demonstração de poder. No caso do SwissPass, a verdade está relacionada ao fato de o aparato "apenas" oferecer benefícios aos cidadãos, sendo considerado um sistema que trouxe o país à era digital, em que a racionalização da tecnologia foi vista como único elemento importante no processo de implantação desse projeto no espaço urbano. Um exemplo claro desse processo de racionalização foi a total desconsideração do aumento de estresse e desconforto dos controladores do sistema público de mobilidade na Suíça, causado pela substituição do antigo sistema pelo SwissPass. Esse grupo social não foi considerado no processo de implantação do novo sistema, o que reforça o argumento de Foucault (2014) sobre a racionalidade e de Luque-Ayala e Marvin (2015) sobre o urbanismo inteligente.

Apesar de o SwissPass ter um impacto social grande pelo potencial do número de usuários atingidos, com mais de 2,2 milhões de cidadãos suíços, seus idealizadores também não consultaram os cidadãos, tampouco os pesquisadores sobre mobilidade, especialistas na área de trânsito, sociólogos ou engenheiros, justificando que não havia necessidade de uma consulta, o que demonstra o poder governamental do SBB (líder, idealizador e implantador). Esse fato ratifica a ideia de Foucault (2008), que, por meio da governamentalidade, a sociedade passa a ser resultado de fatores tecnológicos determinados pelos detentores do poder - no caso do SwissPass, uma empresa de mobilidade urbana pública, porém, autônoma. 


\section{[I] https://orcid.org/0000-0001-8215-6524}

Pontifícia Universidade Católica do Paraná, Escola de Arquitetura e Design, Programa de PósGraduação em Gestão Urbana. Curitiba, PR/Brasil.

marcelamoraes.b@gmail.com

\section{[II] https://orcid.org/0000-0002-0831-6603}

Pontifícia Universidade Católica do Paraná, Escola de Arquitetura e Design, Programa de PósGraduação em Gestão Urbana. Curitiba, PR/Brasil.

rodrigo.firmino@pucpr.br

\section{Nota}

(1) "Technological development should be viewed as a social process, not an autonomous occurrence."

\section{Referências}

AIBAR, E. e BIJKER, W. (1997). Constructing a city: the Cerdà plan for the extension of Barcelona science. Technology human values, v. 22, n. 3, pp. 13-30.

BATTY, M. et al. (2012). Smart cities of the future. UCL Working Paper Series, Paper 188.

BAUER, M. W. e AARTS, B. (2002). "A construção do corpus: um princípio para a coleta de dados qualitativos". In: BAUER, M. W. e GASKELL, G. (eds.). Pesquisa qualitativa com texto, imagem e som: um manual prático. Petrópolis/RJ, Vozes.

BIJKER, W. (1995). Of bicycles, bakelites, and bulbs: toward a theory of sociotechnical change. Cambridge/MA/EUA, MIT Press.

BIJKER, W. e LAW, J. (1992). “General Introduction”. In: BIJKER, W. e LAW, J. (eds.). Shaping technology/ building society: studies in sociotechnical change. Cambridge/MA, MIT Press.

CANDIOTTO, C. (2010). Governamentalidade política no pensamento de Foucault. Filosofia Unisinos, v. 11, n. 1 , pp. 33-43.

ELLIOTT, A. e URRY, J. (2010). Mobiles lives. Londres, Routledge.

FIRMINO, R. (2011). Cidade ampliada: desenvolvimento urbano e tecnologias da informação e comunicação. São Paulo, Hedra.

FIRMINO, R.; DUARTE, F. e ULTRAMARI, C. (2010). ICTs for mobile and ubiquitous urban infrastructures: surveillance, locative media and global networks. Nova York, IGI Global.

FLÜGGER, B. (2017). Smart mobility: Connecting everyone. Springer. 
FOUCAULT, M. (1983). "The subject and power". In: DREYFUS, H. L. e RABINOW, P. Michel Foucault: beyond structuralism and hermeneutics. Second Edition with an Afterword by and an Interview with Michel Foucault. Chicago, The University of Chicago Press.

(1991). "Governmentality". In: GRAHAM, B.; GORDON, C. e MILLER, P. (eds.). The Foucault effect. Chicago, IL, University of Chicago Press.

(2000). Em defesa da sociedade: curso no Collège de France (1975-1976). São Paulo, Martins Fontes.

(2008). Segurança, território, população. Curso no Collège de France (1977-1978). São Paulo, Martins Fontes.

(2014). Microfísica do poder. Rio de Janeiro, Graal.

FOT (2017). Safety Division. Disponível em: https://www.bav.admin.ch/bav/en/home/the-fot/theoffices-tasks/safety/the-division-of-safety-duties-in-the-public-transport-sector.html. Acesso em: 24 set 2017 .

GAO, W. et al. (2016). Possibility and challenge of smart community in Japan. Procedia - Social and Behavioral Sciences, n. 216, pp. 109-118.

GORDON, C. (1991). "Governamentality". In: GRAHAM, B.; GORDON, C. e MILLER, P. (eds.). The Foucault effect: studies in governamentality. Chicago/IL, The University of Chicago Press.

GRAHAM, S. e MARVIN, S. (1996). Telecommunications and the city: electronic spaces, urban places. Londres, Routledge.

(2001). Splintering Urbanism: Networked Infrastructures, Technological Mobilities and the Urban Condition. Londres, Routledge.

HALL, R. (2000). The vision of a smart city. In: 2ND INTERNATIONAL LIFE EXTENSION TECHNOLOGY WORKSHOP. Paris, september.

HARDT, M. e NEGRI, A. (2009). Commonwealth. Cambridge, Harvard University Press.

HARRISON,C. et al. (2010). Foundation for smarter cities. IBM. Journal of research and development, v. $54, \mathrm{n} 4$.

HOLLANDS, R. (2008). Will the real smart city please stand up? Intelligent, progressive or entrepreneurial? City, v. 12, n. 3, pp. 303-320.

HOWCROFT, D. e LIGHT, B. (2010). The social shaping of packaged. Software selection, v. 11, n. 3, pp. 122-148.

KITCHIN, R. (2014). "From a single line of code to an entire city: reframing thinking on code and the city". In: CODE AND THE CITY WORKSHOP. Programmable City. National University of Ireland Maynooth, 3rd-4th sep.

KITCHIN, R.; LAURIAULT, T. P. e MCARDLE, G. (2016). "Smart city and the politics of urban data". In: MARVIN, S.; LUQUE-AYALA, A. e MCFARLANE, C. (eds.). Smart urbanism: utopian vision or false dawn? Londres e Nova York, Routledge.

KLAUSER, F.; PAASCHE, T. e SÖDERSTRÖM, O. (2014). Michel Foucault and the smart city: power dynamics inherent in contemporary governing through code. Environment and Planning $D, v .32$, n. 5, pp. 869-885. 
KOMNINOS, N. (2011). Intelligent cities variable geometries of special intelligent. Intelligent Building internacional, v. 3, n. 3, pp. 172-188.

KRIVÝ, M. (2018). Towards a critique of cybernetic urbanism: The smart city and the society of control. Planning Theory, v. 17, n. 1, pp. 8-30.

LATOUR, B. (2005). "From realpolitik to dingpolitik". In: LATOUR, B.; WEIBEL, P. Making things public. Cambridge, MIT Press.

LEMKE, T. (2001). The birth of biopolitics. Michel Foucault's lecture at the collège de France on neo-liberal governmentality. Economy and Society, v. 30, n. 2, pp. 190-207.

LUQUE-AYALA, A. e MARVIN, S. (2015). Developing a critical understand of smart urbanism. Urban Studies, v. 52, n. 12, pp. 2105-2116.

LUQUE-AYALA, A; MCFARLANE, C. e MARVIN, S. (2016). “Introduction”. In: MARVIN, S.; LUQUE-AYALA, A. e MCFARLANE, C. (eds.). Smart urbanism: utopian vision or false dawn? Londres e Nova York, Routledge.

MARRES, N. e ROGERS, R. (2005). "Recipe for tracing the fate of issues and their publics on the web". In: LATOUR, B.; WEIBEL, P. (eds.). Making things public: atmospheres of democracy. Cambridge MIT Press.

NAM, T. e PARDO, T. A. (2011). Smart city as urban innovation: focusing on management, policy and context. 5a CONFERÊNCIA INTERNACIONAL SOBRE TEORIA E PRÁTICA DA GOVERNANÇA ELETRÔNICA - ICEGOV. Anais. Tallinn, Estonia.

PINCH, T. e BIJKER, W. (1984). "The social construction of facts and artifacts: or how the sociology of science and the sociology of technology might benefit each other". In: PINCH, T.; BIJKER, W. e HUGHES, T. The social construction of technological systems. Cambridge, Massachusetts Institute of Technology.

(1987). "The social construction of facts and artifacts: or how the sociology of science and the sociology of technology might benefit each other". In: PINCH, T.; BIJKER, W. e HUGHES, T. The social construction of technological systems. Cambridge, Massachusetts Institute of Technology.

POLLIO, A. (2016). Smart cities as hacker cities: organized urbanism and restructuring welfare in crisisridden Italy. Revista de Ciencias Sociales y Humanidades, v. esp.

ROSE, N. (1999). Powers of freedom: reframing political thought. Nova York, Cambridge University Press.

ROSE, M. H e TARR, J. A. (2004). Introduction: technology, politics, and structuring of the city. Journal of Urban History, v. 30, n. 5, pp. 643-647.

SBB. General abonnement. Disponível em: https://www.sbb.ch/en/travelcards-and-tickets/railpasses/ ga.html. Acesso em: 20 set 2017.

SWISS TRAVEL (2017). Swiss Travel System - SwissPass.

TARR, J. A. (1979). Introduction. Journal of Urban History, v., 5, n. 3, pp. 275-278.

VANOLO, A. (2014). Smartmentality: the smart city as disciplinary strategy. Urban Studies, v. 51, n. 5, pp. 883-898. 
VENTURINI, T. (2009). Diving in magma: how to explore controversies with actornetwork theory. Public Understanding of Science, v. 19, n. 3, pp. 258-273.

(2012). Building on faults: how to represent controversies with digital methods. Public Understanding of Science, v. 21, n. 7, pp. 796-812.

VENTURINI, T.; RICCI, D.; MAURI, M.; KIMBELL, L. e MEUNIER, A. (2015). Designing controversies and their publics. Design Issues, v. 31, n. 3, pp. 74-87.

YIN, R. K. (1994). Case study research design and methods. Thousand Oaks. CA, Sage Publications.

Texto recebido em 19/nov/2018

Texto aprovado em 13/dez/2018 